\title{
DIURNAL PATTERNS OF THE BI-DIRECTIONAL REFLECTANCE OF FRESH-WATER ICE
}

\author{
by \\ George A. Leshkevich, \\ (Great Lakes Environmental Research Laboratory, U.S. Department of Commerce,
} National Oceanic and Atmospheric Administration, Ann Arbor, MI 48105, U.S.A.)

Donald W. Deering,

(Earth Resources Branch/623, NASA Goddard Space Flight Center, Greenbelt, MD 20771, U.S.A.)

Thomas F. Eck and Suraiya P. Ahmad

(ST Systems Corporation, 4400 Forbes Boulevard, Lanham, MD 20706, U.S.A.)

\section{ABSTRACT}

To improve the interpretation of surface cryospheric albedo from satellite sensor data, diurnal measurements of the spectral bi-directional reflectance of a commonly-found fresh-water ice type were made, from which hemispherical reflectance can be derived. The purpose of this study is to document its clear-sky, bi-directional reflectance characteristics in the visible $(650-670 \mathrm{~nm})$ and near-infrared $(810-840 \mathrm{~nm})$ region, assess the diurnal nature of the reflectance, and quantify the surface anisotropy. Bidirectional reflectances of the re-frozen slush ice measured show a spectral dependence and change significantly with solar zenith angle. Considerable variation occurs at each view angle and among view angles throughout the day. Although diurnal reflectance patterns were similar in both bands, magnitudes varied greatly, being highest in the visible and lowest in the near-infrared region. With the exception of peak saturated (specular) values in the forward scatter direction, bi-directional reflectance was generally highest in the morning when the surface and the illumination were most diffuse in character. The exitance $(\pi \mathrm{N})$ computed from nadir radiance $(\mathrm{N})$ is compared to the measured hemispheric exitance (M). The $\pi \mathrm{N} / \mathrm{M}$ ratios, an index of anisotropy, reveal an anisotropy that increases with increasing solar zenith angle and is more pronounced in the near-inf rared region.

\section{INTRODUCTION}

In a recent study of surface albedo parameterization in climate models, Robinson and others (1983) concluded that present data sets do not adequately account for the highly variable nature of surface albedo in time and space. They suggested that satellite sensors provide the best source for these data, but that without extensive, well-documented ground data, the usefulness of satellite surveillance is restricted.

Five distinctly different scene reflectance characteristics (spectral, spatial, angular, temporal, and polarized) are described by Gerstl and Simmer (1986). Polarization is not generally considered as it has not been widely measured by satellite sensors in the visible and near-infrared. Although the influence of the atmosphere must be taken into account in airborne and satellite remote sensing, they and other authors, including Ott and others (1984), have demonstrated the value of angular (directional) reflectance data or "angular signatures" in the interpretation of aircraft and satellite sensor data.
The bi-directional reflectance of snow is a relatively well-documented phenomenon. However, the bi-directional reflectance of fresh-water ice types, which involve the interactions of solar zenith and azimuth angles, view angle, diurnal and temporal physical parameter changes (surface metamorphosis), and sky conditions has been less well documented. The purpose of this study is to document the clear-sky, bi-directional reflectance in the visible and near-infrared region of re-frozen slush ice, a commonly found fresh-water ice type, assess the diurnal characteristics of the reflectance, and quantify the surface anisotropy. A database containing such measurements, acquired for different ice and snow surface types, could improve interpretation of these different surface types using satellite sensor data (Leshkevich, 1985) and improve the estimation of hemispheric reflectance from satellite observations of the Earth-atmosphere system (Kimes and others, 1987), a parameter needed for climate and radiation budget models for the shortwave spectrum (Suttles and Ohring, 1986).

\section{INSTRUMENTATION AND METHODS}

Measurements of the diurnal bi-directional radiances from a re-frozen slush ice surface were acquired using a sphere-scanning spectro-radiometer, the Portable Apparatus for Rapid Acquisition of Bi-directional Observations of the Land and Atmosphere, or PARABOLA. The PARABOLA is a two-axis rotating head, three-channel (visible, near-infrared, and mid-infrared) motor-driven radiometer that enables the acquisition of radiance data for the nearly complete $(4 \pi)$ sky- and ground-looking hemispheres in 15 instantaneous field-of-view (IFOV) sectors in only $11 \mathrm{~s}$. The three sensors include two silicon and one germanium solid state detectors, which with the filters used $(650-670 \mathrm{~nm}$, $810-840 \mathrm{~nm}$, and $1620-1690 \mathrm{~nm}$, respectively) correspond approximately to Landsat TM spectral bands 3,4 , and 5 . The PARABOLA instrument, data recording unit, and support systems have been described in detail by Deering and Leone (1986). For this study, the instrument boom $(5.5 \mathrm{~m}$ long) was mounted on a tripod such that the PARABOLA was approximately $4.2 \mathrm{~m}$ from the surface. Using this configuration, the nadir circular IFOV "footprint" was $1.1 \mathrm{~m}$ in diameter.

Two complete PARABOLA replicate samples were taken at each of three surface positions one meter apart at approximately every $5^{\circ}$ of solar zenith angle ranging from maxima of $70.6^{\circ}$ at $08.48 \mathrm{~h}$ EST (Eastern Standard Time) and $63.7^{\circ}$ at $16.03 \mathrm{~h}$ EST to a minimum of $47.3^{\circ}$ at $13.13 \mathrm{~h}$ EST. These were averaged for each viewing angle to 
minimize any within-field inhomogeneity effects. Two replicates at each of the three adjacent locations were considered adequate in this study as the surface sampled was chosen to be homogeneous and the PARABOLA pixel instantaneous fields-of-view (IFOV surface areas) are large (ranging from $0.95 \mathrm{~m}^{2}$ at nadir to $83.0 \mathrm{~m}^{2}$ at $75^{\circ}$ ) relative to the surface structure. The average of the six values was used as the surface radiance for a particular view direction. Off-nadir viewing angles used in the analysis were limited to a maximum of $75^{\circ}$. With a $15^{\circ}$ IFOV, the surface pixels with a radiance centroid of $75^{\circ}$ include radiance contributions extending out to $82.5^{\circ}$. The PARABOLA was rotated to maintain the same orientation relative to the solar azimuth. Bi-directional [e.g. (direct sun + diffuse sky)directional] reflectance factors were computed using the PARABOLA directional radiance measurements from the ground-looking hemisphere divided by the irradiance incident on a barium sulfate reference panel corrected for non-Lambertian panel response.

\section{SITE CHARACTERISTICS AND SKY CONDITIONS}

Field measurements were made at a site on an inland lake (lat. $45.58^{\circ} \mathrm{N}$, long. $84.67^{\circ} \mathrm{W}$ ) in northern Michigan on 15 March 1987. The snow covering the lake during midFebruary (14.0 to $20.3 \mathrm{~cm}$ at the measurement site) became water-soaked from rain and rain mixed with snow that occurred during the middle to latter part of February and early March. Water forced up through stress cracks in the ice due to hydrostatic pressure may have contributed to further saturation of the snow cover in some areas. This layer then froze solid so that, by 15 March, the frozen slush layer, grayish-white in color and characterized by a myriad of bubbles of various sizes and distributions, measured $7.6 \mathrm{~cm}$ on top of $33.0 \mathrm{~cm}$ of clear or black ice. Temperatures for the day averaged slightly below freezing (mean of $-2{ }^{\circ} \mathrm{C}$ ) but reached a maximum of $2^{\circ} \mathrm{C}$ at $13.15 \mathrm{~h}$ EST. Mean wind speed was $9 \mathrm{~km}^{-\mathrm{h}}\left(2.5 \mathrm{~m} \mathrm{~s}^{-1}\right)$ from the east-southeast gusting on occasion to $39 \mathrm{~km}^{-\mathrm{h}}\left(10.8 \mathrm{~m} \mathrm{~s}^{-1}\right)$.

On the day of measurement, there was no snow remaining on the lake surface, except for a few isolated patches of old, granular snow. The measurement site chosen was centered in a homogeneous expanse of re-frozen slush ice, whose surface was smooth but gently undulating (i.e. non-shadow producing). One of the most noticeable characteristics was the frost-coating that settled on the ice during the night. As a result, in the morning the ice surface looked matte in appearance (diffuse reflector). As the sun got higher in the sky, this matte surface became more specular in appearance. By late morning there was a very thin film of water on the surface that could be felt when rubbing one's fingers on the ice. This film became more pronounced by mid-afternoon, although no standing water occurred.

Data were collected throughout the day under virtually cloudless sky conditions. An extremely light haze and a very light cirrus formation on the horizon to the northeast were noticeable in the early morning but subsequently cleared by mid-morning. Diffuse sky irradiance was determined from unshaded and shaded barium sulfate reference panel measurements taken at each PARABOLA data set measurement time. The daily variation in the diffuse or sky component of the irradiance in the visible band ranged from a maximum of $15.4 \%$ at $08.36 \mathrm{~h}$ EST to $7.4 \%$ at $14.14 \mathrm{~h}$ EST, increasing to $10.7 \%$ at $16.46 \mathrm{~h}$ EST. Solar noon occurred at $12.48 \mathrm{~h}$ EST at a $46.9^{\circ}$ zenith angle.

\section{RESULTS, DISCUSSION AND CONCLUSIONS}

Reflected radiance data measured in the solar principal plane in two narrow spectral bands in the visible and near-infrared region (centered at $662 \mathrm{~nm}$ and $826 \mathrm{~nm}$, respectively) were analyzed. Data in the mid-infrared band $(1658 \mathrm{~nm})$ showed little variation compared to the visible and near-infrared bands and are not considered in this study. In describing a snow surface, Dirmhirn and Eaton (1975), Warren (1982), Dozier and others (1988), and other authors point out that the processes of reflectivity depend on surface and sub-surface (volumetric) radiation scattering and absorption characteristics. In addition, the relative contribution of the specular and diffuse components of reflected radiation varies with the physical characteristics of the material, solar zenith angle, and view angle. Accompanying the change in solar zenith angle, under clear skies, is the change in the proportions of direct and diffuse illumination and the variation in irradiance distribution (Kriebel, 1976). Similar to snow surfaces, the bi-directional reflectance of re-frozen slush ice shows a spectral dependence and changes significantly with solar zenith angle. Mullen and Warren (1988) have inferred from radiative transfer modeling of lake ice that near-infrared albedo is dominated by surface reflection while multiple scattering from sub-surface bubbles dominates visible albedo.

\section{Nadir and backscatter view angles}

Following the decrease in solar zenith angle, the reflectance in the visible band as measured from the nadir view angle increases rapidly during the mid-morning reaching a maximum of 0.42 about one hour before solar noon, as shown in Figure 1. It then decreases steadily during the afternoon. In the near-infrared band, the reflectance reaches a maximum of 0.28 about two hours before solar noon then slowly decreases to $14.25 \mathrm{~h}$, when it starts to fall more rapidly. It does not show as pronounced a sun angle dependence as in the visible band. Using nadirand zenith- looking pyranometers, Bolsenga (1980) measured the diurnal variation of the total solar spectrum $(300-3000 \mathrm{~nm})$ albedo for re-frozen slush ice under various sky conditions. He concludes that there is a pronounced daily variation of albedo for re-frozen slush ice under clear skies, but a lack of variation under cloudy skies. When compared to reflectance from the nadir view, which increases and decreases with increasing and decreasing sun angle, reflectance in both bands at the $30^{\circ}$ and $45^{\circ}$ backscatter view angles increases to mid-morning then decreases to just past solar noon, subsequently increasing to a secondary maximum in the afternoon before decreasing with increasing solar zenith angle. The highest reflectances occur in the morning for all three view angles and are higher than those measured in the afternoon at approximately the same solar zenith angles. Hubley (1955) reports the same phenomenon for albedos of snow surfaces under clear sky illumination. He also notes that midday albedos of snow were higher under cloudy skies (diffuse illumination) than under clear skies. In the morning, the ice surface on the lake was most diffuse in character owing to the frost coating deposited on the surface during the night. It is also the time when the greatest percentage of diffuse sky illumination occurred. These are probable reasons why backscatter radiation is greatest in the early to mid-morning. As the solar zenith angle decreases, the direct

\section{Solar Zenith Angle $\left({ }^{\circ}\right)$}

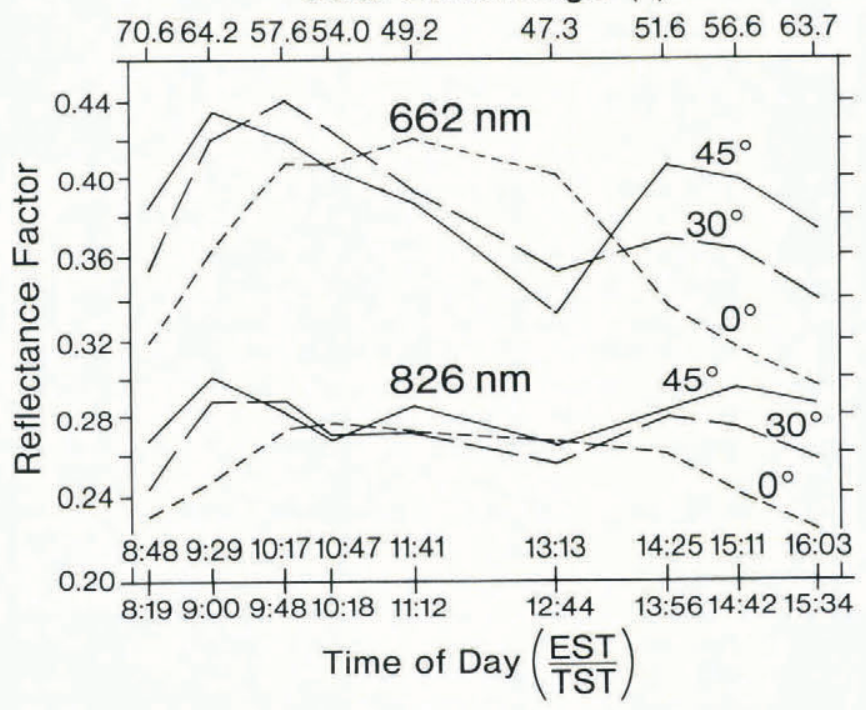

Fig. 1. Reflectance from re-frozen slush ice in the visible $(662 \mathrm{~nm})$ and near-infrared $(826 \mathrm{~nm})$ bands for nadir and two backscatter view angles $\left(30^{\circ}\right.$ and $\left.45^{\circ}\right)$ as a function of time of day. 


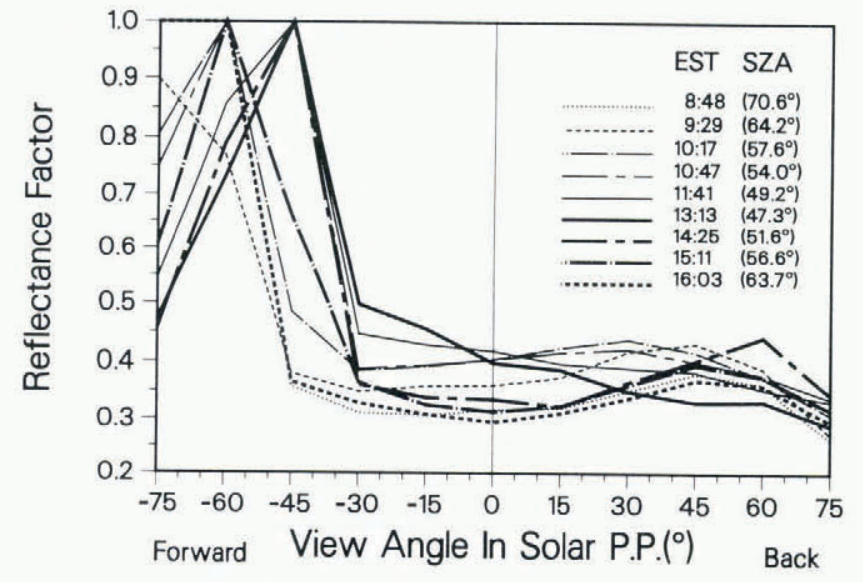

Fig. 2. Reflectance from re-frozen slush ice in the visible $(662 \mathrm{~nm})$ band as a function of view angle in the solar principal plane.

component of the irradiance increases and the surface undergoes a morphosis with the increase in temperature, becoming more specular in character. The secondary maximum in the backscatter direction with increasing solar zenith angle (mid-afternoon) likely occurs as a result of scattering from the near-surface bubble structure and the gently undulating character of the surface. This phenomenon is not observed from the nadir view.

\section{Forward scatter view angle}

Figure 2 shows the data plotted in $15^{\circ}$ increments of forward scatter and backscatter view angle in the solar principal plane. The diurnal progression of reflectance at each view angle can be followed along the vertical axis for each respective view angle. The most apparent phenomena is the high specular reflectance in the forward scatter direction. Since the PARABOLA detectors reached saturation in all three channels when viewing in the specular direction, these values have been scaled down in the graphic illustrations in order to show the variability at other view angles.

In the $45^{\circ}$ forward scatter view angle, morning reflectance increases slowly to 0.49 at $10.17 \mathrm{~h}$, then rises sharply to peak saturated values at $10: 47 \mathrm{~h}$ and maintains this character until $14.25 \mathrm{~h}$, subsequently decreasing rapidly. At a $60^{\circ}$ forward scatter view angle, the early morning measurement $(8.48 \mathrm{~h})$ drops from a peak saturated value to about 0.77 at $9.29 \mathrm{~h}$, subsequently increasing to peak saturated values at $10.17 \mathrm{~h}$ and $10.47 \mathrm{~h}$. These fall to an average 0.79 reflectance for the measurements just before to just after solar noon $(11.41 \mathrm{~h}, 13.13 \mathrm{~h}, 13.25 \mathrm{~h})$. It is interesting to note that for these same measurement times at a $45^{\circ}$ forward scatter view angle, the reflectance has reached peak saturated values and is completely specular in character. As solar zenith angle increases, the reflectance in the $60^{\circ}$ forward scatter view angle again reaches peak saturated values at $15.11 \mathrm{~h}$ and $16.03 \mathrm{~h}$. In comparison, the diurnal cycle of bi-directional reflectance at a $75^{\circ}$ forward scatter view angle is entirely different than at the $45^{\circ}$ or $60^{\circ}$ view angles. Owing to the large solar zenith and view angles, the early morning measurement $(8.48 \mathrm{~h})$ at the $75^{\circ}$ view angle attains a peak saturated value even though the ice surface is still relatively diffuse at this time. Reflectance then falls from 0.90 at $9.29 \mathrm{~h}$ to 0.46 at $14.25 \mathrm{~h}$, subsequently increasing to a peak saturated value at $16.03 \mathrm{~h}$ (solar zenith angle $=63.7^{\circ}$ ). The $11^{\circ}$ sun angle $/$ view angle difference can be attributed to both ice surface structure and large pixel size at this view angle. Thus, reflectance reaches a peak saturated value at a forward scatter angle close to the same solar zenith angle and maintains that relationship throughout the day.

\section{Anisotropic surface characteristics}

The characteristics and dynamics of the surface reflectance throughout the day are more fully revealed when the features of the bi-directional reflectance distribution function (BRDF) (Nicodemus and others, 1977), visually represented using three-dimensional graphic plots, are examined. The approximate BRDF "surfaces" for the two spectral bands and for two solar zenith angles $\left(64.2^{\circ}\right.$ and $47.3^{\circ}$ ) are plotted in Figure 3 . These reveal substantial changes in the anisotropic character of the ice surface. Although the diurnal reflectance patterns are similar in both bands, it is apparent that not only the magnitude but also the distribution of the reflectance from the surface changes with solar zenith angle and to a lesser extent with wavelength. The specular peak is prominent in both bands throughout the day, but is of greater proportion in the distribution of surface reflectance, compared to other surface reflectance features, at larger solar zenith angles.

The $\pi \mathrm{N} / \mathrm{M}$ ratio, the ratio of the exitance estimated from a single direct nadir radiance $(\mathrm{N})$, (assuming a surface with Lambertian characteristics) and the total hemispheric upwelling exitance (M), has been used as a measure or index of the anisotropy associated with a surface at a given solar zenith angle under given atmospheric conditions and is more fully described by Middleton and others (1987). It is used here to quantify and describe the interaction of radiation with the refrozen slush ice surface. A perfectly Lambertian surface would yield a value of 1.0. Anisotropy is indicated when the ratio yields values other than 1.0. The total hemispheric exitance is computed from the upwelling radiances measured by the PARABOLA instrument (explained by Middleton and others (1987)) which include peak saturated values in the specular direction. To calculate total hemispheric exitance the magnitude of these numbers must be known. The values used in this computation were measured in 1988, using neutral density filters over the PARABOLA sensor cones. Although the bubble structure (porosity) of the re-frozen slush ice layer may have

TABLE I. TOTAL IRRADIANCE, HEMISPHERIC EXITANCE, NADIR ANISOTROPY, AND HEMISPHERIC REFLECTANCE FOR RE-FROZEN SLUSH ICE AT MORNING, NEAR NOON, AND AFTERNOON SUN ANGLES, 15 MARCH 1987

\begin{tabular}{|c|c|c|c|c|c|c|c|}
\hline \multirow[t]{2}{*}{$\begin{array}{l}\text { Solar } \\
\text { zenith } \\
\text { angle }\end{array}$} & \multirow[t]{2}{*}{$\begin{array}{l}\text { Hemispheric } \\
\text { irradiance } \\
\mathrm{Wm}^{-2} \mu \mathrm{m}^{-1}\end{array}$} & \multicolumn{2}{|c|}{$\begin{array}{l}\text { Hemispheric } \\
\text { exitance } \\
\mathrm{Wm}^{-2} \mu \mathrm{m}^{-1}\end{array}$} & Anisotropy & \multicolumn{2}{|c|}{$\begin{array}{l}\text { Hemispheric } \\
\text { reflectance } \\
\text { (\%) computed from }\end{array}$} & \multirow{2}{*}{$\begin{array}{c}\% \text { error } \\
\text { compute } \\
\pi \mathrm{N}\end{array}$} \\
\hline & & M & $\pi \mathrm{N}$ & $\pi \mathrm{N} / \mathrm{M}$ & M & $\pi \mathrm{N}$ & \\
\hline \multicolumn{8}{|c|}{ Channel $1(\lambda=0.65-0.67 \mu \mathrm{m})$} \\
\hline 64.2 & 867 & 350 & 313 & 0.89 & 40.4 & 36.1 & -10.6 \\
\hline 47.3 & 1302 & 542 & 520 & 0.96 & 41.6 & 39.9 & -4.1 \\
\hline 63.7 & 882 & 332 & 260 & 0.78 & 37.6 & 29.5 & -21.7 \\
\hline \multicolumn{8}{|c|}{ Channel $2(\lambda=0.81-0.84 \mu \mathrm{m})$} \\
\hline 64.2 & 494 & 160 & 122 & 0.76 & 32.4 & 24.7 & -23.8 \\
\hline 47.3 & 745 & 233 & 198 & 0.85 & 31.3 & 26.6 & -15.0 \\
\hline 63.7 & 503 & 157 & 113 & 0.72 & 31.2 & 22.5 & -28.0 \\
\hline
\end{tabular}




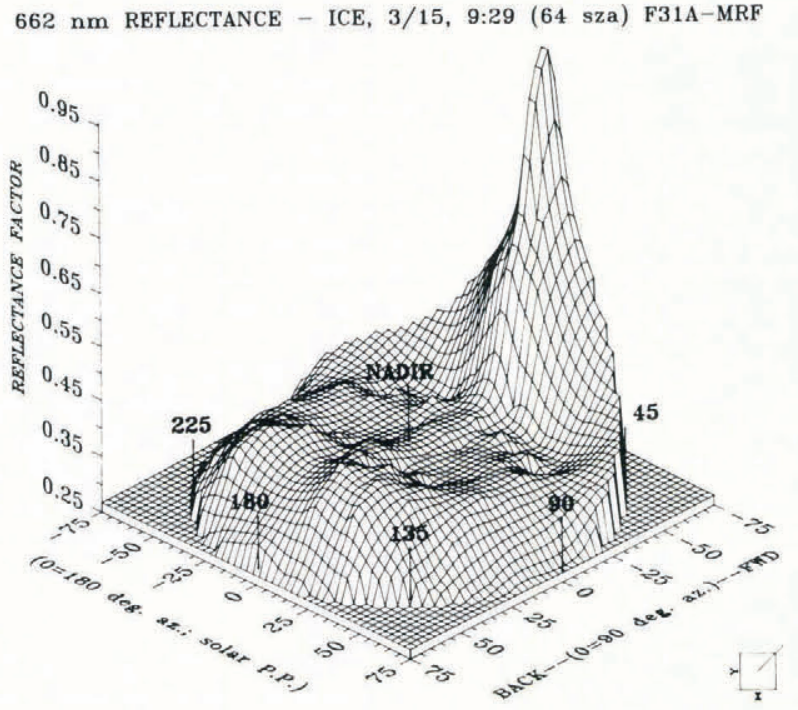

$662 \mathrm{~nm}$ REFLECTANCE - ICE, 3/15, 13:13 (47 sza) G31A-MRFX

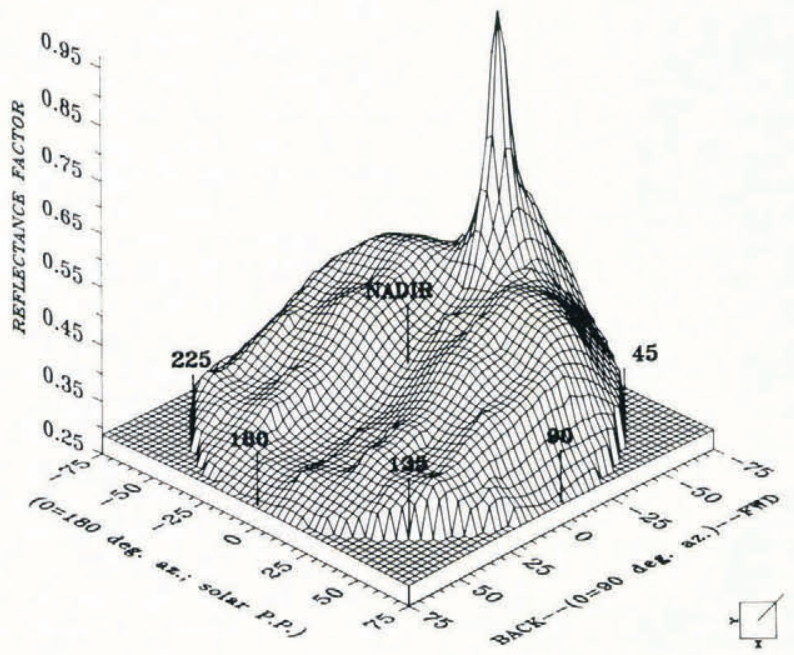

$662 \mathrm{~nm}$ REFLECTANCE - ICE, 3/15, 9:29 (64 sza) F31A-MRF

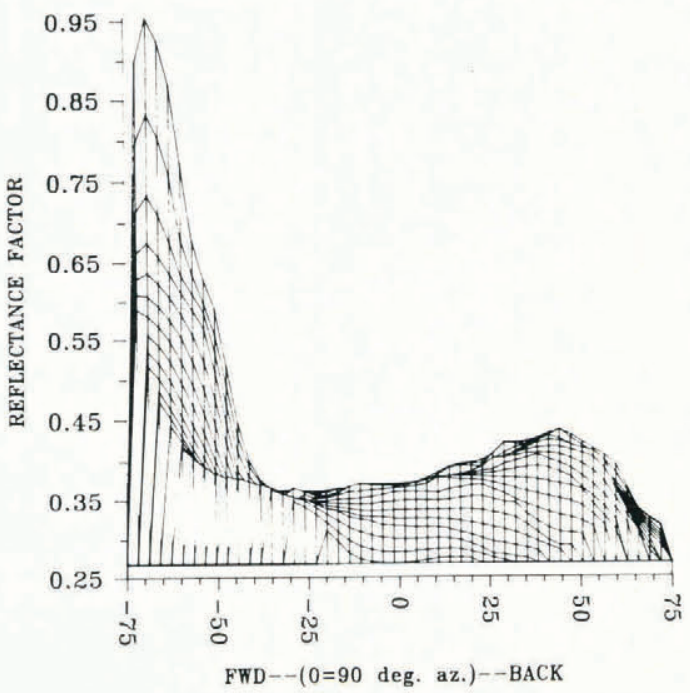

$662 \mathrm{~nm}$ REFLECTANCE - ICE, 3/15, 13:13 (47 sza) G31A-MRFX

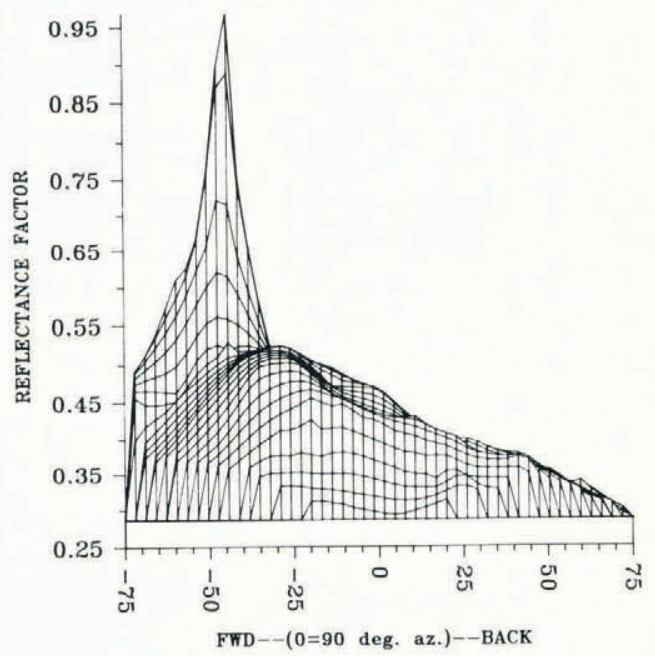

A

Fig. 3. Bi-directional reflectance surfaces (perspective views) for re-frozen slush ice in (A) the visible band $(662 \mathrm{~nm})$ at solar zenith angles of $64.2^{\circ}$ at $09: 29 \mathrm{~h}$ (top) and $47.3^{\circ}$ at $13.13 \mathrm{~h}$ EST (bottom) and (B) the near-infrared band $(826 \mathrm{~nm})$ at the same solar zenith angles. Perspective plots have been rotated $180^{\circ}$ from conventional orientation to prevent the peak specular reflectance (scaled down to 1.00) from obscuring the surface.

differed somewhat from that measured in 1987, causing a possible difference in scattering, the measurements were made at the same site, over the same ice type, and at nearly the same solar zenith angles as the measurements described in this paper. Ice thickness and stratigraphy and sky conditions were relatively close to those during the 1987 measurements. It is assumed, therefore, that the values measured in the specular direction are comparable to the 1987 values.

Table I summarizes hemispheric and nadir data, nadir anisotropy and hemispheric reflectance for the re-frozen slush ice surface at morning, near noon, and afternoon sun angles. As $\pi \mathrm{N}$ increasingly underestimates $M$ with increasing solar zenith angle in both bands, hemispherical reflectances computed using $\pi \mathrm{N}$ are increasingly underestimated. The $\pi \mathrm{N} / \mathrm{M}$ ratios for the re-frozen slush ice surface reveal an anisotropy that increases with increasing solar zenith angle, but is greater in the afternoon than in the morning, and is more pronounced in the near-infrared region.

\section{ACKNOWLEDGEMENTS}

The authors express their appreciation to Robert VandeKopple and Tony Sutterly of the University of Michigan Biological Station at Douglas Lake for providing a base of operations, meteorological data during our field measurements, and various support equipment.

\section{REFERENCES}

Bolsenga, S.J. 1980. New observations on the daily variations of natural ice albedo. NOAA Tech. Memo. ERL GLERL-27.

Deering, D.W. and P. Leone. 1986. A sphere-scanning radiometer for rapid directional measurements of sky and ground radiance. Remote Sensing Environ., 19(1), 1-24.

Dirmhirn, I. and F.D. Eaton. 1975. Some characteristics of the albedo of snow. J. Appl. Meteorol., 14(3), $375-379$. 
826 nm REFLECTANCE - ICE, 3/15, 9:29 (64 sza) F31B-MRF

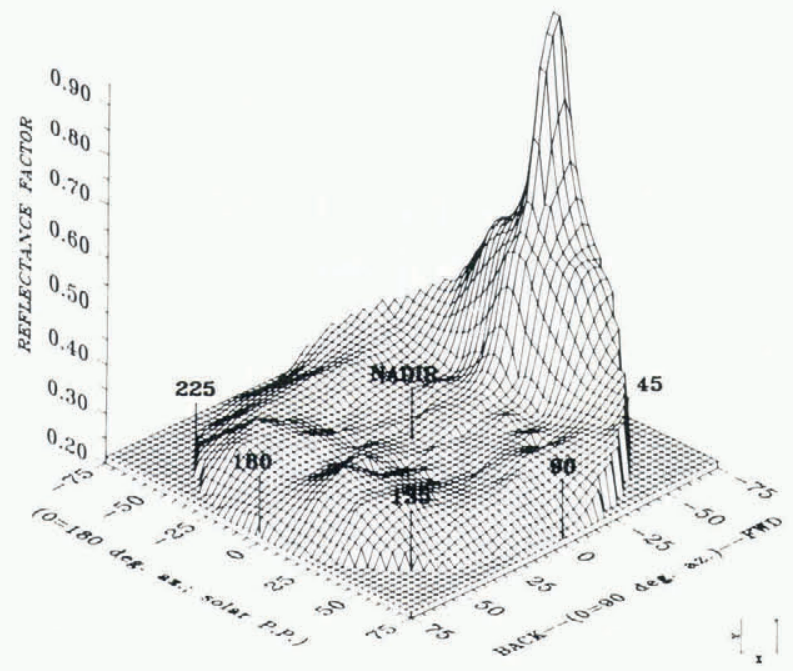

$826 \mathrm{~nm}$ REFLECTANCE - ICE, 3/15, 13:13 (47 sza) G31B-MRF

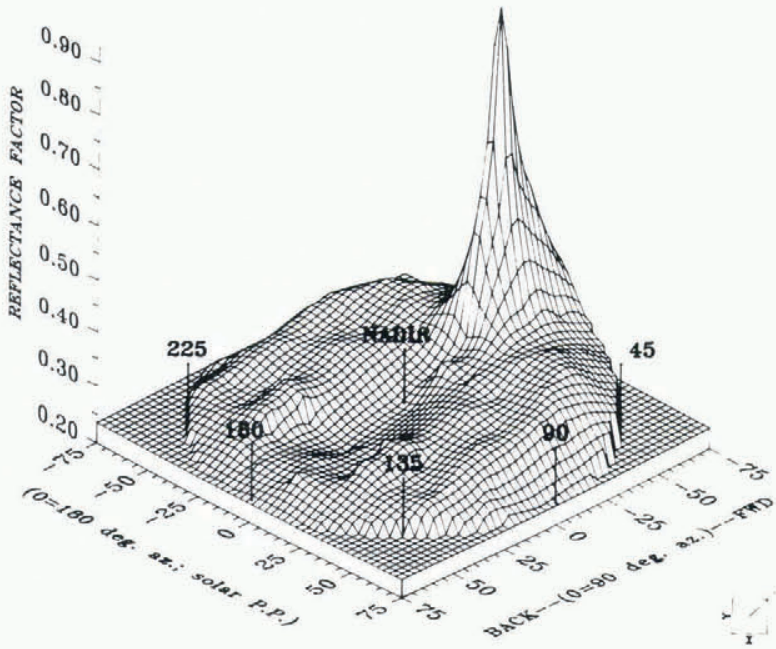

B
$826 \mathrm{~nm}$ REFLECTANCE - ICE, 3/15, 9:29 (64 sza) F31B-MRF

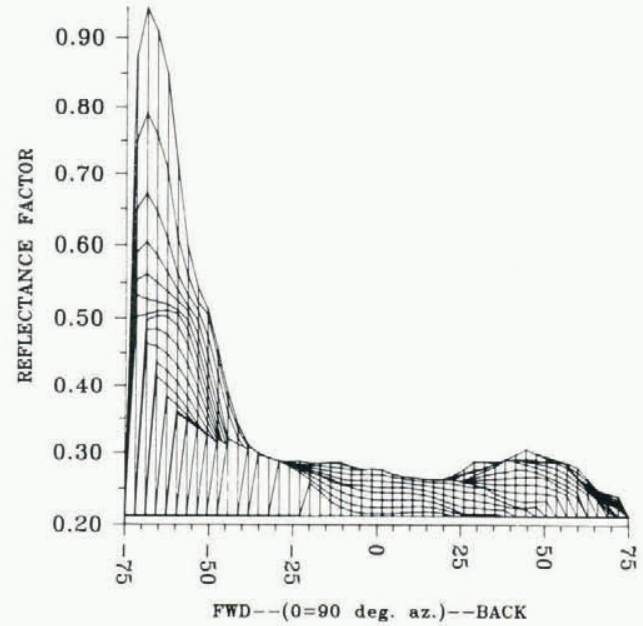

$826 \mathrm{~nm}$ REFLECTANCE - ICE, 3/15, 13:13 (47 sza) G31B-MRF

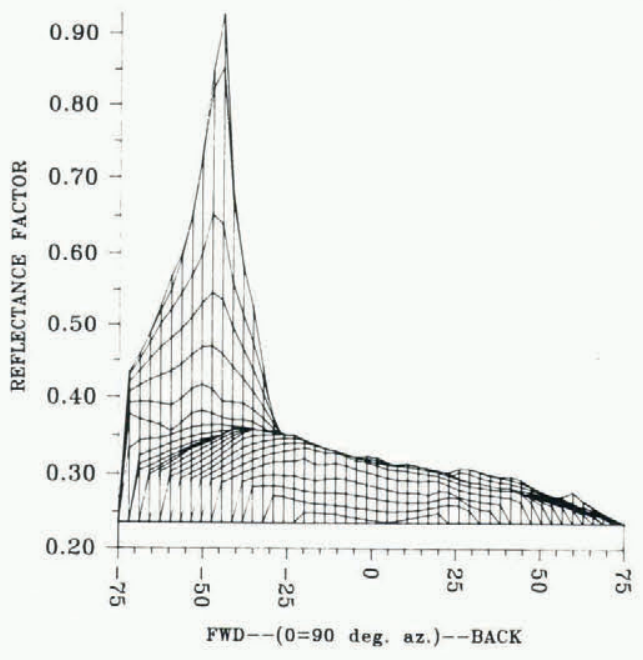

Dozier, J., R.E. Davis, A.T.C. Chang, and K. Brown. 1988. The spectral bidirectional reflectance of snow. In Proceedings of the 4 th International Colloquium on Spectral Signatures of Objects in Remote Sensing. Paris, European Space Agency, 87-92. (ESA SP-287.)

Gerstl, S.A.W. and C. Simmer. 1986. Radiation physics and modelling for off-nadir satellite-sensing of nonLambertian surfaces. Remote Sensing Environ., 20(1), 1-29.

Hubley, R.C. 1955. Measurements of diurnal variations in snow albedo on Lemon Creek Glacier, Alaska. J. Glaciol., 2(18), 560-563.

Kimes, D.S., P.J. Sellers, and D.J. Diner. 1987. Extraction of spectral hemispherical reflectance (albedo) of surfaces from nadir and directional reflectance data. Int. J. Remote Sensing, 8(12), 1727-1746.

Kriebel, K.T. 1976. On the variability of the reflected radiation field due to differing distributions of the irradiation. Remote Sensing Environ., 4(4), 257-264.

Leshkevich, G.A. 1985. Machine classification of freshwater ice types from Landsat-1 digital data using ice albedos as training sets. Remote Sensing Environ., 17(3), 251-263.

Middleton, E.M., D.W. Deering, and S.P. Ahmad. 1987. Surface anisotropy and hemispheric reflectance for a semiarid ecosystem. Remote Sensing Environ., 23(2), 193-212.

Mullen, P.C. and S.G. Warren. 1988. Theory of the optical properties of lake ice. J. Geophys. Res., 93(D7), 8403-8414.

Nicodemus, F.F., J.C. Richmond, J.J. Hsia, I.W. Ginsberg, and T.L. Limperis. 1977. Geometrical considerations and nomenclature for reflectance. Washington, DC, U.S. Government Printing Office. (National Bureau of Standards Monograph 160.)

Ott, W., B. Pfeiffer, and F. Quiel. 1984. Directional reflectance properties determined by analysis of airborne multispectral scanner data and atmospheric correction. Remote Sensing Environ., 16(1), 47-54.

Robinson, D., M. Wilson, G. Kukla, and A. HendersonSellers. 1983. Observation of surface albedo and its variation for climate models. In Proceedings of the Seventeenth International Symposium on Remote Sensing of Environment. Vol. 2. Ann Arbor, MI, Environmental Research Institute of Michigan, 469-477.

Suttles, J.T. and G. Ohring, eds. 1986. Surface radiation budget for climate applications. Washington, DC, National Aeronautics and Space Administration. (Reference Publication 1169.)

Warren, S.G. 1982. Optical properties of snow. Rev. Geophys. Space Phys., 20(1), 67-89. 